Anuario de

Derechos Humanos 2005 


\section{A propósito de las Leyes 19.963 y 19.964 , que modifican la Ley 19.884 sobre Transparencia, Límite y Control del Gasto Electoral}

Javier Couso Salas*

\section{Introducción}

D urante el año 2004, el Congreso Nacional aprobó dos cuerpos legales (la Ley $N^{\circ} 19.963$ y la Ley $N^{\circ} 19.964$ ), que modificaron la Ley $N^{\circ} 19.884$, de agosto del 2003, de financiamiento de las campañas electorales. Atendido que las normas legales mencionadas más arriba vienen a complementar y eliminar defectos y omisiones de la ley que modifican (en particular la falta de sanciones de que adolecía esta última, así como otras cuestiones técnicas de menor importancia), este comentario comienza analizando la pertinencia y relevancia de la Ley $N^{0} 19.884$, que por primera vez en nuestra historia introdujo en nuestro país legislación dirigida a transparentar, limitar y controlar el gasto electoral. Hecho esto, se analiza críticamente un aspecto crucial de la legislación modificatoria.

\section{Antecedentes Teórico-Normativos}

Uno de los desafíos más importantes que enfrentan las democracias contemporáneas -sean estas consolidadas o nacientes- es asegurar que el momento paradigmático de la democracia, el sufragio, se desarrolle en un contexto coherente con los valores que subyacen a aquella, como la igualdad, la garantía de emitir el voto libre de presiones, la transparencia, y el acceso a información relevante. En efecto, sin estas condiciones aun el más eficiente y ordenado proceso de votación y escrutinio sería insuficiente para catalogar un proceso eleccionario como cabalmente democrático.

Si bien durante las últimas décadas se ha avanzado mucho en la expansión universal de normas electorales que aseguren un conteo fidedigno de las votaciones populares incluso en países con escasa o nula tradición democrática (con el apoyo de organismos de Naciones Unidas y organizaciones no gubernamentales, como el Centro Carter), existe todavía mucho trecho por recorrer en lo que dice relación con la "democratización" del proceso que antecede al día de la elección, particularmente en el ámbito de las financiación de las campañas políticas.

Dado lo arcano que suele ser este tópico, es importante subrayar que detrás del rótulo aparentemente técnico que lo identifica
* Abogado, Profesor de Derecho y Sociología, Universidad Diego Portales.
Este comentario, junto con el documento principal a que se refiere, están disponibles en formato digital en www.anuariocdh.uchile.cl 
("financiamiento electoral"), se esconde uno de los desafíos más serios que enfrentan las democracias contemporáneas, a saber, el peligro de la "captura" de los procesos electorales por intereses particulares dotados del enorme poder e influencia que otorga el dinero, que ahora puede corromper el proceso democrático de manera tanto o más efectiva que las antiguas prácticas de cohecho que tanto preocuparon a nuestros antepasados. Lo difícil de nuestra situación actual es que el impacto disruptivo de los procesos democráticos que tiene el dinero, a través del financiamiento de campañas por parte de grupos económicos que después "cobran" el favor a quienes resultan elegidos utilizando el expediente del lobby, ha resultado ser mucho más difícil de confrontar que el cohecho.

Por otra parte, y atendido que el problema de la captura de la política por parte de intereses corporativos que financian las campañas electorales tiene ya cierta data, cabe preguntarse por qué sólo recientemente este tópico ha suscitado tanto interés. Para el caso de las democracias latinoamericanas, la explicación que propone el cientista político Carlos Huneeus es sugerente. De acuerdo a este último (Huneeus, 1996), el efecto corruptor del dinero en los procesos eleccionarios se habría agudizado durante las últimas dos décadas por el efecto combinado de dos procesos paralelos: la caída del poder de convocatoria de los partidos políticos y la constitución de poderosos grupos económicos, como resultado de los procesos de privatización de la economía de esta región, los que cuentan con poderosos incentivos para "capturar rentas", esto es, obtener beneficios económicos gracias a legislación o a actos administrativos que incrementan sus ingresos sin un aumento de productividad de sus empresas. Eso explicaría el aumento de la presión empresarial por buscar influir en el proceso político. Más allá de si la tesis planteada por Huneeus es o no finalmente confirmada, existe coincidencia entre politólogos y observadores de los procesos eleccionarios en que el dinero juega cada día un mayor rol en las campañas políticas, tanto en países con democracias consolidadas como las en "transición".

En este punto es bueno hacer una pausa, y subrayar que la tensión entre dinero y democracia es a su vez consecuencia de la colisión de una serie de elementos entre sí. En primer término, el choque entre la lógica eminentemente igualitaria de la democracia y la concentración económica característica de la economía de mercado. En segundo lugar, el contraste entre el ideal deliberativo que subyace a la teoría democrática -que enfatiza la necesidad de votantes debidamente informados antes de emitir su voto- $y$ la efectividad del marketing de la era en que vivimos que, por el contrario, cultiva la irreflexión de los votantes, apelando a imágenes y símbolos, y no a promover la discusión de ideas. Lo complicado de estos conflictos es que, entregados a su suerte, los aspectos menos apetecibles tienden a prevalecer, despejándole el camino a los intereses que intentan reproducir el poder económico que detentan en la esfera política, 
para lo que derrochan grandes energías y recursos monetarios en un marketing político que sustituye la deliberación por maniobras comunicacionales y de imagen corporativa que a la vez seducen y atontan a los ciudadanos.

Sintetizando este rápido recorrido por los contornos de un debate mucho más vasto (y cuyo tratamiento sistemático demandaría mayor espacio que el previsto para este artículo), esto es, el de los problemas que plantea la relación entre el dinero y la política en el ámbito de las campañas electorales, se puede concluir que existen buenas razones para regular la misma pormenorizadamente, buscando preservar los valores fundamentales de la democracia frente a los irreprimibles intentos de círculos con poder económico de dominar también esos dominios.

Quizá por lo señalado recién, los países con mayor grado de desarrollo de sus prácticas democráticas (como los países escandinavos y otros del noroeste europeo) han introducido ya desde hace varias décadas legislación dirigida a fijar límites a los gastos electorales y a igualar el acceso de las diferentes candidaturas a la atención del votante mediante el financiamiento público de las campañas. En el caso de las democracias latinoamericanas, la preocupación por estas cuestiones es más reciente, aunque a la fecha ya existe una vasta gama de legislación sobre este tópico en la mayoría de ellos. El problema en América Latina, sin embargo, es la consabida dificultad de esta región de lograr que la nutrida legislación aprobada sea respetada en la práctica, cambiando efectivamente la conducta de las personas, de manera que los elevados ideales que proclaman las normas introducidas hagan una diferencia.

\section{La ley Chilena sobre Financiamiento Electoral}

En el caso de Chile, la situación era hasta hace sólo unos años aún peor, ya que la regulación del financiamiento de la política era casi inexistente, restringiéndose a una muy limitada ley de financiamiento de los partidos políticos, que no reguló en absoluto la relación entre el dinero y el financiamiento de las campañas políticas, mientras elección tras elección aumentaban los montos gastados por los candidatos a todo tipo de cargos de elección popular.

Como suele suceder en la vida política de las naciones, la situación solo vino a cambiar producto de una crisis de proporciones, el denominado "Caso MOP-GATE" el cual -aunque sólo tangencialmente vinculado al financiamiento electoral- llevó al gobierno y a la oposición a consensuar una ambiciosa agenda de transparencia y probidad política, de una entidad que no se había visto desde el retorno de la democracia, que incluyó cerca de treinta iniciativas legales y administrativas dirigidas a aumentar la transparencia en la gestión del Estado y a combatir la corrupción. Dentro de este verdadero "paquete" de reformas institucionales se incluyó un proyecto sobre transparencia, control y límites de gastos electorales sin precedentes, dirigido precisamente a paliar el lamentable vacío regulatorio hasta entonces existente. 
Como resultado de este esfuerzo legislativo, en agosto del 2003 finalmente se aprobó la Ley $N^{\circ} 19.884$, sobre transparencia, límite y control del gasto electoral, que por primera vez en nuestra historia electoral introdujo cambios sustanciales a la forma en que se financian las campañas políticas en nuestro país. Entre las más importantes reformas al financiamiento electoral destacan las siguientes: a) límites al gasto que los candidatos a cargos de elección popular pueden hacer en una campaña determinada; b) límites a las donaciones que entidades particulares pueden hacer a un candidato determinado; c) la obligación de hacer público el origen de la mayoría de las donaciones a campañas electorales; y d) el subsidio estatal de parte del costo de campaña de los candidatos, así como muchas otras dirigidas al control y transparencia de las relaciones del dinero y la política.

Sin perjuicio del avance innegable que la Ley № 19.884 representó para intentar regular el financiamiento electoral en Chile-y por razones que no es posible detallar aquí- el mencionado cuerpo legal no incluyó sanciones para disciplinar a quienes transgredieran las numerosas obligaciones establecidas, lo cual fue considerado por los especialistas como algo inaceptable, puesto que haría de la mencionada legislación letra muerta (Fuentes, 2004). Este defecto es precisamente el objetivo central de la Ley $N^{\circ} 19.963$, que incorpora una serie de multas para los candidatos que violen esta última, amén de establecer que el Servicio Electoral estará encargado de aplicar tales sanciones.

En relación a este último punto, cabe señalar que es realmente lamentable que no se haya aprovechado la oportunidad para buscar sanciones más disuasivas que la mera imposición de multas, lo que para grupos con gran poder económico se convierte simplemente en un costo más de la operación por influenciar las políticas públicas del país. En este sentido, se echa de menos que la legislación que viene a complementar la Ley № 19.884 no hubiera establecido que el candidato que transgreda las reglas del juego democrático sea eliminado de la competencia electoral por el Servicio Electoral, quedando inhabilitado para presentarse en el futuro. En nuestra opinión, sólo una sanción de este tipo garantizaría la imposibilidad de que personas financiadas por intereses corporativos que intentan obtener rentas accedan a los cargos de representación popular.

En el caso de la segunda ley que complementa la ley de financiamiento electoral, la Ley $N^{\circ} 19.964$, las modificaciones son menores y de carácter técnico, básicamente dirigidas a perfeccionar los mecanismos burocráticos necesarios para implementar las obligaciones y prohibiciones establecidas en la Ley $N^{\circ} 19.884$. 